\title{
Design and Assessment of a Lightweight Polymer Concrete Utility Manhole
}

\author{
Luciano Leonardi, ${ }^{1}$ Teresa M. Pique $\mathbb{D}^{\mathrm{D}},{ }^{1,2}$ Tomas Leizerow, ${ }^{2}$ Humberto Balzamo, ${ }^{2}$ \\ Celina Bernal, ${ }^{1,2}$ Analía Vazquez, ${ }^{1,2}$ and Eliana Agaliotis ${ }^{1}$
}

\author{
${ }^{1}$ Universidad de Buenos Aires, Facultad de Ingeniería, Buenos Aires, Argentina \\ ${ }^{2}$ Instituto de Tecnología de Polímeros y Nanotecnología (ITPN), Universidad de Buenos Aires/CONICET, \\ Buenos Aires, Argentina
}

Correspondence should be addressed to Teresa M. Pique; tpique@fi.uba.ar

Received 23 May 2019; Revised 26 July 2019; Accepted 6 September 2019; Published 13 October 2019

Academic Editor: Zhonghua Yao

Copyright (c) 2019 Luciano Leonardi et al. This is an open access article distributed under the Creative Commons Attribution License, which permits unrestricted use, distribution, and reproduction in any medium, provided the original work is properly cited.

\begin{abstract}
Polymer concrete is a composite using polymer instead of portland cement as a binder. It allows optimizing the tensile and cracking strength and the chemical resistance of a concrete structure. In this study, different formulations were assessed in order to optimize a polymer concrete underground utility manhole with minimum weight. Formulations were based on an epoxy-amine system mixed with fine regular-weight aggregates and ultralightweight aggregates. The objective was to design and assess an underground utility structure with the epoxy chemical resistance, strength, and lightweight and to study whether the replacement of regular-weight aggregates by ultralightweight aggregates would contribute to improve the strength and reduce the structure weight. Two polymer concrete systems were designed from its formulation, and their mechanical performance was evaluated experimentally. A numerical model was developed for a polymer concrete underground utility structure made from the different formulations. It was simplified as a box subjected to typical soil loads. The size of the box is a standard one. Its minimum wall thickness is specified for sustaining the in-use service pressures obtained from numerical simulation. The model predicted that the epoxy/regular-weight aggregate formulation could be used with a wall thickness significantly smaller than the formulation with ultralightweight aggregates. In addition, the underground utility structure made with this formulation would weigh six times less than the same box made with a traditional portland cement concrete.
\end{abstract}

\section{Introduction}

Polymer concrete is a composite material where the binder is a thermosetting polymer reinforced with aggregates. It was developed in 1970 responding to the need of a lightweight material with high compressive strength and good chemical resistance $[1,2]$. Vibration damping is also another polymer concrete relevant property [3].

There are several uses of precast polymer concrete such as drains, tanks, manholes [3], restoration building [4, 5], pavements [6], and underground utility structures [1], among others. The final properties of polymer concrete depend on its design and production conditions such as the type of binder, the mixing method, and the type and size distribution of the aggregates. The binder of polymer concrete is usually a thermosetting resin; hence, the viscosity and the gel time of the resin are also important preparation factors [7].

The thermosetting polymers used for polymer concrete are unsaturated polyester (UP), vinyl ester (VE), methyl methacrylate (MMA), furan resin (FU), and epoxy resins [3]. The unsaturated polyester and vinyl ester are low-cost resins; however, the common use of styrene for their cross-linking makes them difficult to work with because of its high volatility. Other cross-linking agents were also used instead of styrene, but the glass transition temperature $\left(T_{\mathrm{g}}\right)$ decreased and the material exhibited inferior mechanical properties. For example, Mironi-Harpaz et al. [8] analyzed the use of peroxide as a crosslinking agent. However, the cross-linking reactions occurred together with scission events, and the polymer presented gel 
and sol fractions. The sol fraction acted as a plasticizer, reducing the $T_{\mathrm{g}}$ of the system as well as its modulus and strength. MMA was also used because it has good workability and high reactivity, but it presents high flammability and unpleasant odor such as UP and VE [9]. Another thermosetting polymer commonly used for polymer concrete is epoxy [10-12]. It has no volatiles, presents different reactivity degrees depending on the curing agent, and higher chemical resistance compared to UP resin [13].

Jafari et al. [14] developed polymer concrete (PC) using different polymer ratios, from 10 to $14 \mathrm{wt} . \%$. They evaluated the mechanical behavior of PC using destructive and nondestructive (NDT) tests. Mixtures were prepared with three different polymer ratios $(10 \%, 12 \%$, and $14 \%)$ and two different coarse aggregate sizes (4.75-9.5 $\mathrm{mm}$ and 9.5$19 \mathrm{~mm}$ ). The binder was an epoxy reactive system, and the main conclusion was that the use of a higher polymer ratio and aggregate size led to better mechanical properties and reduced porosity of the specimens.

Hollow glass microspheres are wildly used to form syntactic epoxy foams with a very low specific weight $[15,16]$. It has also been reported that PET pellets can satisfactorily reduce the specific weight of the epoxy polymer mortar [11]. Nevertheless, the strength of the final material can be reduced when these aggregates are used $[11,15,16]$.

Nóvoa et al. [17] studied the mechanical response of two lightweight polymer mortar formulations obtained by replacing the sand content with cork aggregates. They observed a linear decrease in the materials mechanical properties with the decrease of the sand content. Furthermore, they found that the decrease of density obtained by replacing sand with cork lead to a smoother loss in the specific properties.

Table 1 presents a comparison between the mechanical properties of traditional portland cement concrete and PC presented by Czarnecki $[18,19]$. It reveals that the use of PC with traditional aggregates leads to a better performing material. This is particularly important for underground applications such as optical fiber connection utility structures, whose transportation costs can represent a significant portion of the total costs when the final destination is far removed from the site of manufacture. Currently, these utility structures are made of portland cement concrete and the rather elevated weight of the structure makes their transportation very expensive.

The present study deals with the design and assessment of a PC based on an epoxy system and two different types of fine aggregates: traditional aggregates (fine ground quartz and fine and coarse sand) and nontraditional aggregates (PET pellets and hollow glass microspheres). The PC formulations were designed to minimize the density of a utility manhole with sufficient strength. The mechanical properties of the resulting material were measured, and by means of a finite element model, their application in an underground utility structure was evaluated. All the dimensions of simulated structure remained constant but the wall thickness. The minimum wall thickness was established to withstand typical soil pressures in order to obtain a low-weight but resistant polymer concrete utility manhole.
TABle 1: Properties of cement concrete and polymer concrete adapted from Czarnecki and Lukowski [18] and Czarnecki [19].

\begin{tabular}{lcc}
\hline Property & $\begin{array}{c}\text { Cement } \\
\text { concrete }\end{array}$ & $\begin{array}{c}\text { Polymer } \\
\text { concrete }\end{array}$ \\
\hline Compressive strength, $\mathrm{MPa}$ & $10-60$ & $40-150$ \\
Flexural strength, MPa & $1.5-7$ & $4-50$ \\
Tensile strength, MPa & $0.6-3.0$ & $4-20$ \\
Modulus of elasticity, GPa & $15-30$ & $7-45$ \\
Poisson's ratio & $0.11-0.21$ & $0.16-0.33$ \\
Water absorbability, \% & $4-10$ & $0.5-3$ \\
Chemical resistance & Poor/average & Very good/excellent \\
\hline
\end{tabular}

\section{Materials and Methods}

2.1. Materials. An epoxy resin with an amine-based hardener was selected as the binder. The epoxy and the amine were provided by Novarchem S.A. (Argentina) with the trade name of DICAST 867 and DICURE 383, respectively. Dicast 867 is a reactive diluent containing low-viscosity bisphenol A/F-based monofunctional epoxy resin. The hardener DICURE 383 is a cycloaliphatic polyamine.

Traditional aggregates such as coarse sand (fineness modulus 2.96), fine sand (fineness modulus 1.86), and fine quartz powder were used (Figure 1(a)). Furthermore, to achieve the lowest final density of the utility manhole, lightweight nontraditional aggregates such as polyethylene terephthalate (PET) thermoplastic pellets $(2.5 \mathrm{~mm} \times 2.9 \mathrm{~mm} \times 2 \mathrm{~mm})$ and hollow glass microspheres $\left(d_{50}=40 \mu \mathrm{m}\right)$ were used as well (Figure 1(b)). Their properties are presented in Table 2, and its gradation (ASTM C 136 [20]) is shown in Table 3.

The polymer concrete was designed with 80 wt.\% of solids and 20 wt.\% of the chosen epoxy/hardener system. Since there is no aggregate retained on the $\mathrm{N}^{\circ} 4$ sieve, the composite it is actually a polymer mortar, but since in the Polymer Concrete Technology the two terms are frequently used interchangeably, it will be called polymer concrete. The amount of resin system was chosen as the maximum recommended $[10,14]$ in order to achieve the lower viscosity of the composite during its processing and the lower final weight. In addition, the higher the solid to binder ratio, the better the final properties [14].

\subsection{Experimental Methods}

2.2.1. Resin System Characterization. The determination of the optimum value of the epoxy/hardener was chosen using differential scanning calorimetry (DSC). The ratio of the system with maximum enthalpy change was selected [21]. DSC was performed in a Shimadzu DSC 60 analyzer at $10^{\circ} \mathrm{C} /$ min under nitrogen atmosphere at $30 \mathrm{ml} / \mathrm{min}$ in order to determine the epoxy/hardener ratio [22]. The resin glass transition temperature $\left(T_{\mathrm{g}}\right)$ was also determined by DSC at a heating rate of $10^{\circ} \mathrm{C} / \mathrm{min}$ under nitrogen atmosphere.

To determine gelation time $\left(t_{\mathrm{gel}}\right)$ of the epoxy/ hardener system, a set of thin tubes (2 $\mathrm{mm}$ diameter) 


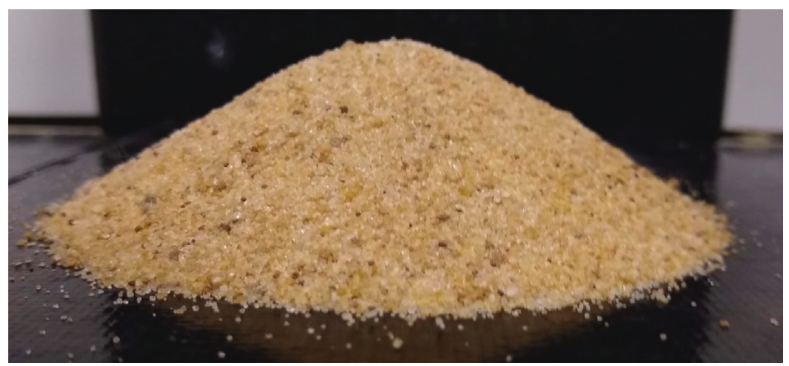

(a)

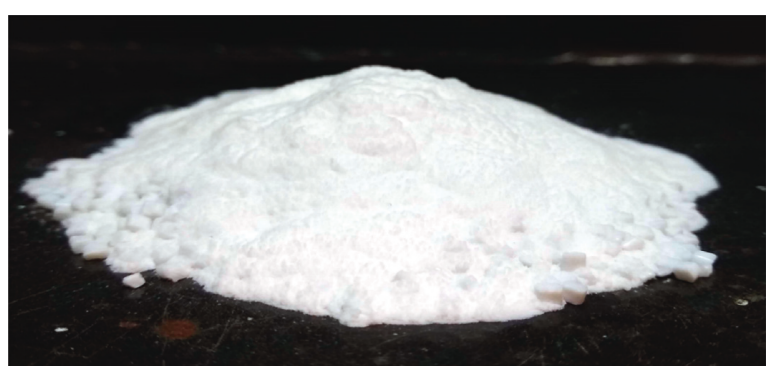

(b)

FIGURE 1: (a) Traditional aggregates (ground quartz and fine and coarse natural sand) and (b) lightweight nontraditional aggregates (PET pellets and hollow glass microspheres).

TABLE 2: Traditional and nontraditional aggregates properties.

\begin{tabular}{lccc}
\hline & Bulk density $\left(\mathrm{g} / \mathrm{cm}^{3}\right)$ & Voids $(\%)$ & Density $\left(\mathrm{g} / \mathrm{cm}^{3}\right)$ \\
\hline Fine sand & 1.547 & 41.20 & 2.630 \\
Coarse sand & 1.600 & 39.20 & 2.630 \\
Quartz & 1.329 & 49.80 & 2.650 \\
PET pellets & 0.811 & 39.77 & 1.346 \\
Hollow glass microspheres & 0.226 & 34.20 & 0.350 \\
\hline
\end{tabular}

TABle 3: Sand and quartz gradation.

\begin{tabular}{lccc}
\hline \multirow{2}{*}{ Sieve size } & \multicolumn{3}{c}{ Retained on the sieve (\%) } \\
& Fine sand & Coarse sand & Quartz \\
\hline No. 4 & 0.0 & 0.0 & 0.0 \\
No. 8 & 2.9 & 13.1 & 0.0 \\
No. 16 & 7.7 & 355.7 & 0.0 \\
No. 30 & 16.2 & 60.9 & 0.0 \\
No. 50 & 62.0 & 88.7 & 0.0 \\
No. 100 & 96.9 & 98.0 & 0.0 \\
No. 200 & 100.0 & 100.0 & 100.0 \\
Bottom & 100.0 & 100.0 & 100.0 \\
Fineness modulus & 1.86 & 2.96 & - \\
\hline
\end{tabular}

containing it were maintained at constant temperature in a water bath. $t_{\text {gel }}$ is the time at which the whole tube was lifted up by gently pulling a thin wire immersed in the sample [22].

2.2.2. Optimum Aggregate Mixture Determination. In order to optimize the amount of binder, the highest density was sought for aggregate mixtures. Therefore, a continuous particle size distribution was designed with the minimum amount of voids. Ground quartz and fine and coarse natural sand were used to obtain the optimum aggregate combination by following ASTM C125 [23] recommendations. The standard specifies that materials should be well mixed and placed in a calibrated volume container to determine their bulk density (noncompacted and standardized compacted). Knowing each aggregate density, the solid volume was obtained. Finally, comparing this volume with the volume of the container, the percentage of voids and the mixture's apparent volume were determined. Mixture with minimum amount of voids was selected as the optimum one.
2.2.3. Polymer Concrete Composites Preparation and Characterization. After determining the epoxy/hardener ratio and the optimum aggregate mixture, two polymer concrete formulations were designed. Formulation 1 is a polymer concrete with 20 wt.\% of the epoxy/hardener system and 80 wt.\% of an optimum mixture of ground quartz and fine and coarse natural sand. Formulation 2 is a polymer concrete with 20 wt.\% of the epoxy/hardener system and 80 wt.\% of an optimum mixture of hollow glass microspheres and PET pellets. Formulations were characterized thermally, by means of DSC and mechanically, measuring their flexural and compressive strength. The processing of the test specimens consisted on mixing, molding, and curing.

The binder and the selected aggregates were mixed in a Spar SP-500 planetary mixer at ambient conditions $\left(25^{\circ} \mathrm{C}\right.$, $60 \% \mathrm{HR})$. Initially, solids were mixed at $60 \mathrm{rpm}$. Then, the resin was added, and the mixing speed was maintained for 2.5 minutes at $145 \mathrm{rpm}$. Finally, the hardener was incorporated, and all components were mixed at $190 \mathrm{rpm}$. Since the formulation with sand and quartz (Formulation 1) did not present an acceptable completion, the mixing procedure was changed for this formulation, and it was performed in a similar fashion as conventional cement mortars [24]. Resin was initially mixed with the hardener for 2 minutes at $60 \mathrm{rpm}$. Previously homogenized solids were then added to the epoxy system and mixed together for two minutes at $145 \mathrm{rpm}$. Given that the viscosity of the system was low enough, mixtures were cast into $25 \times 25 \times 250 \mathrm{~mm}$ molds without consolidation [25]. For curing, they were kept in a convection oven at $40^{\circ} \mathrm{C}$ during $4 \mathrm{~h}$. They were finally stored at ambient conditions until mechanical testing.

Differential scanning calorimetry (DSC) was additionally performed for the cured formulations in a Shimadzu DSC 60 analyzer at $10^{\circ} \mathrm{C} / \mathrm{min}$ under nitrogen atmosphere at $30 \mathrm{ml} / \mathrm{min}$ in order to determine their glass transition temperature $\left(T_{\mathrm{g}}\right)$. 
Flexural and compressive tests were performed in an INSTRON 5985 dynamometer. Flexural properties were obtained under 3-point bending by following ASTM C 790 [26] standard recommendations. Compressive strength was calculated using equation (1) and flexural strength with equation (2):

$$
\begin{gathered}
\sigma_{\mathrm{c}}=\frac{P}{b d}, \\
\sigma_{\mathrm{f}}=\frac{3 P l}{2 b d^{2}},
\end{gathered}
$$

where $P$ is the peak load, $l$ is the span, $b$ is the width, and $d$ is the thickness of the tested specimen.

At least three square bars, $25 \mathrm{~mm}$ by $25 \mathrm{~mm}$ with a span of $75 \mathrm{~mm}$, were tested at a crosshead speed of $0.5 \mathrm{~mm} / \mathrm{min}$ (Figure 2). Compressive tests on $25 \mathrm{~mm}$ cubes were carried out at a displacement speed of $5 \mathrm{~mm} / \mathrm{min}$ in accordance with ASTM C 579 [27] standard. At least four samples were obtained from the $25 \times 25 \times 250 \mathrm{~mm}$, cut with a saw to achieve the desired sizes (Figure 3 ). These were carefully measured with a caliper gauge $( \pm 0.02 \mathrm{~mm})$. All mechanical tests were performed at ambient conditions.

2.3. Finite Element Model (FEM) Description. A numerical model based on the finite element method (FEM) was used to evaluate the performance of a polymer concrete underground utility structure made with the designed formulations under pre-established soil solicitations. The polymer concrete underground utility structure was simplified as a cubic box. Its size was pre-established but the wall thickness remained as a variable, which was adjusted to give the structure the strength to warrant an adequate in-service performance. Two underground utility structures where simulated, one with the mechanical properties of Formulation 1 (Utility Structure 1) and the other with the mechanical properties of Formulation 2 (Utility Structure 2).

The physical problem under consideration was a cubic box buried at ground level. The three-dimensional model was simulated by using the commercial package Abaqus/ Explicit. The model consisted on a 700-mm side box with the wall thickness variable. The boundary conditions are shown in Figure 4. The mechanical properties of the modeled materials were experimentally obtained for Formulation 1 and Formulation 2.

The total number of elements used was 70000, and the box was discretized by using full-order quadratic brick elements (C3D20) [28]. In order to reduce computational demanding, the model was also tested by simplifying it to a "shell model". The boundary conditions are the same as that in the 3D model. A total of 1296 linear quadrilateral elements of type S4R were used.

In order to simulate the lateral pressure of adjacent soil, three maximum pressures of $5.5 \mathrm{kPa}, 82 \mathrm{kPa}$ and $160 \mathrm{kPa}$ were applied as boundary conditions (Figure 4). These were selected taking into account typical values reported in the literature for soil loads and usually used as the minimum design lateral loads [29]. Moreover, the effect of the variable wall thickness on the

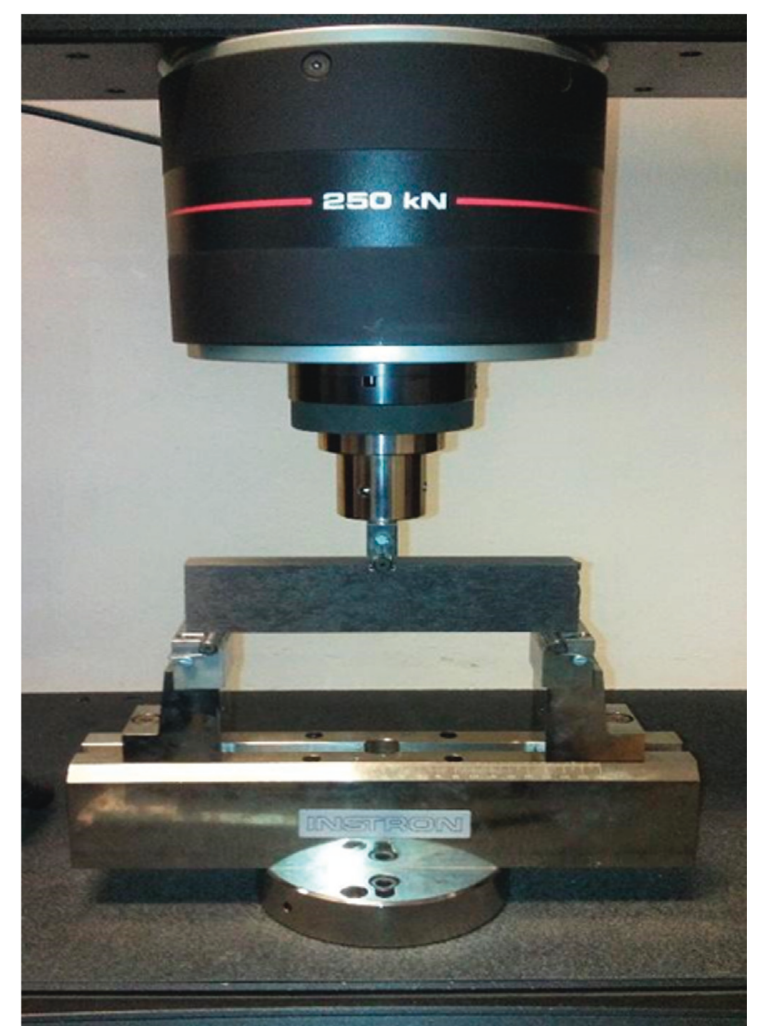

FIgURE 2: Three-point flexural strength test of a Formulation 1 sample.

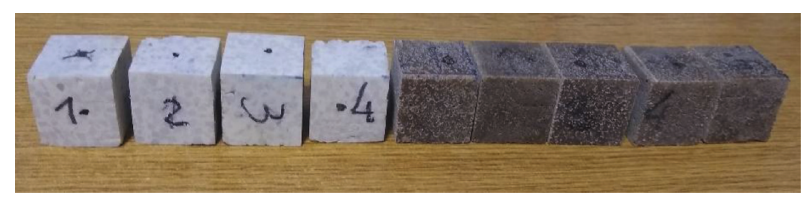

Figure 3: Samples for compression strength test. Formulation 1 samples with sandy color are in the right, and Formulation 2 samples with white color are in the left.

stress distribution was studied by assuming values of $12.7,18$, $25.4,40$, and $50.8 \mathrm{~mm}$ at a pressure of $82 \mathrm{kPa}$ (superior to conventional values [29]). These wall thicknesses were considered as smaller $(12.7 \mathrm{~mm}$ and $18 \mathrm{~mm})$ and higher $(40 \mathrm{~mm}$ and $50.8 \mathrm{~mm}$ ) than $25.4 \mathrm{~mm}$, which is close to the commonly used thickness in commercial structures (Armorcast ${ }^{\circledR}$ ).

The main objective of the analysis was to determine the minimum wall thickness that the polymer concrete underground utility structure built with Formulation 1 and Formulation 2 must have to sustain in-service loading. In addition, stress and displacement distributions of the simplified polymer concrete underground utility structure, with the mechanical properties of Formulations 1 and Formulation 2, were obtained from the model.

\section{Results and Discussion}

\subsection{Experimental Methods}

3.1.1. Epoxy/Hardener Stoichiometric System Selection and Glass Transition Temperature Determination. In order to 


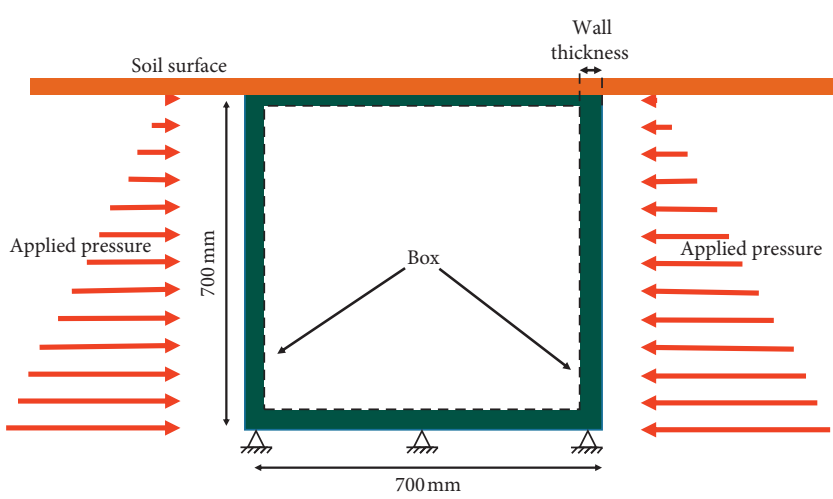

(a)
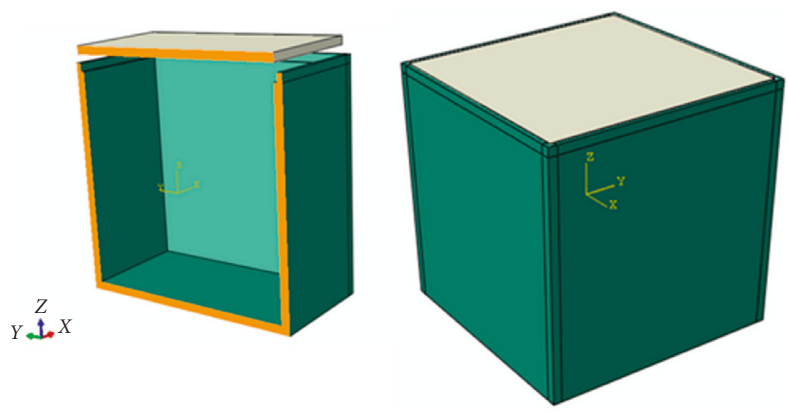

(b)

FIGURE 4: Schematic representation of the polymer concrete underground utility structure simplified as a cubic box: boundary and loading conditions.

determine the most adequate epoxy/hardener stoichiometry ratio, the hardener was added in different amounts and the reaction heat was measured by means of DSC [21] (Figure 5).

The areas underneath the DSC peaks in Figure 5 are proportional to the reaction heat value. The highest value was observed for the 100/35 epoxy/hardener system with a reduced curing temperature range. Therefore, this system was chosen as the binder in the polymer concrete formulations. In addition, since the onset curing temperature was $40^{\circ} \mathrm{C}$, this was chosen as the curing temperature to reduce fabrication costs.

The glass transition temperature $\left(T_{\mathrm{g}}\right)$ is the temperature at which the polymer changes from the glassy state to the rubbery state. It determines the service temperature of the polymer concrete structure since the modulus of the material will deeply decrease at temperatures higher than $T_{\mathrm{g}}$. To determine $T_{\mathrm{g}}$ for the selected system, the chosen epoxy/ hardener system was tested at a heating rate of $10^{\circ} \mathrm{C} / \mathrm{min}$ under a nitrogen atmosphere from room temperature until the reaction ended. It was subsequently cooled down and then heated again (Figure 6). The glass transition temperature was observed as a change in the heat capacity at $75^{\circ} \mathrm{C}$ for the 100/35 epoxy/hardener system.

3.1.2. Resin Gelation Time $\left(t_{g e l}\right)$ Determination. An important parameter when choosing a resin system is the pot life, i.e., the time interval after resin preparation during which a system remains liquid. The resin system gelation time was determined by the wire method [22].

Since gelation time as a function of temperature follows an Arrhenius-type law (equation (3)), natural logarithm of time $[\ln (\mathrm{s})]$ vs $1 / \mathrm{T}[\mathrm{K}]$ (equation (4)) is plotted in Figure 7:

$$
\begin{aligned}
t_{\text {gel }} & =A \cdot e^{\left(-E_{\mathrm{a}} / R T\right)}, \\
\ln t_{\text {gel }} & =\ln (A)-\frac{E_{\mathrm{a}}}{R}\left(\frac{1}{T}\right),
\end{aligned}
$$

where $E_{\mathrm{a}}$ is the activation energy for the reaction, $A$ the preexponential factor, $R$ the universal gas constant, and $T$ the absolute temperature in Kelvin.

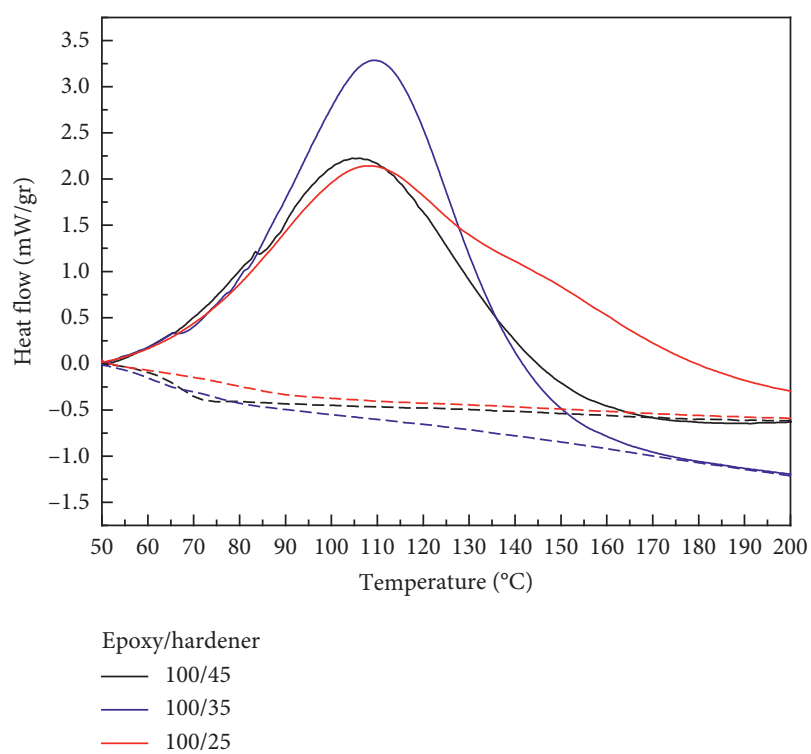

FIGURE 5: DSC scans for the different epoxy/hardener systems investigated, full line during curing (first heating), dash line after curing (second heating).

From the slope of the data of Figure 7, activation energy $\left(E_{\mathrm{a}}\right)$ value of $34.5 \mathrm{~kJ} / \mathrm{mol}$ was obtained. It has been established that as the temperature increases, the gelation time decreases, since it follows a reaction kinetic behavior. Therefore, the temperature when mixing the aggregates and the resin system should be taken into account to estimate the open time of the mixture. If the temperature increases from 20 to $30^{\circ} \mathrm{C}$, the gelation time of the resin system decreases from $2.5 \mathrm{~h}$ to $1.6 \mathrm{~h}$.

3.1.3. Optimum Aggregates Mixture Determination. The optimum mixture for traditional aggregates was determined according to ASTM C125 [23] recommendations. It had a bulk density of $1.75 \mathrm{~g} / \mathrm{cm}^{3}$ with $36 \%$ of voids. It included $23.1 \%$ mass of fine sand, $69.2 \%$ mass of coarse sand, and 7.7\% mass of quartz. The optimum mixture for nontraditional aggregates had a bulk density of $0.77 \mathrm{~g} / \mathrm{cm}^{3}$ with 


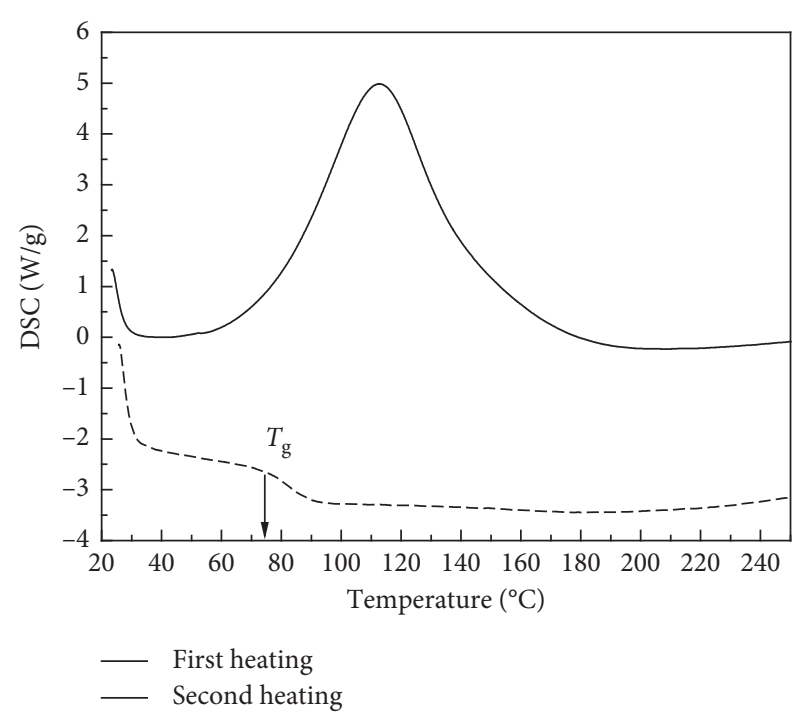

FIGURE 6: Glass transition temperature determination for the 100/ 35 epoxy/hardener system.

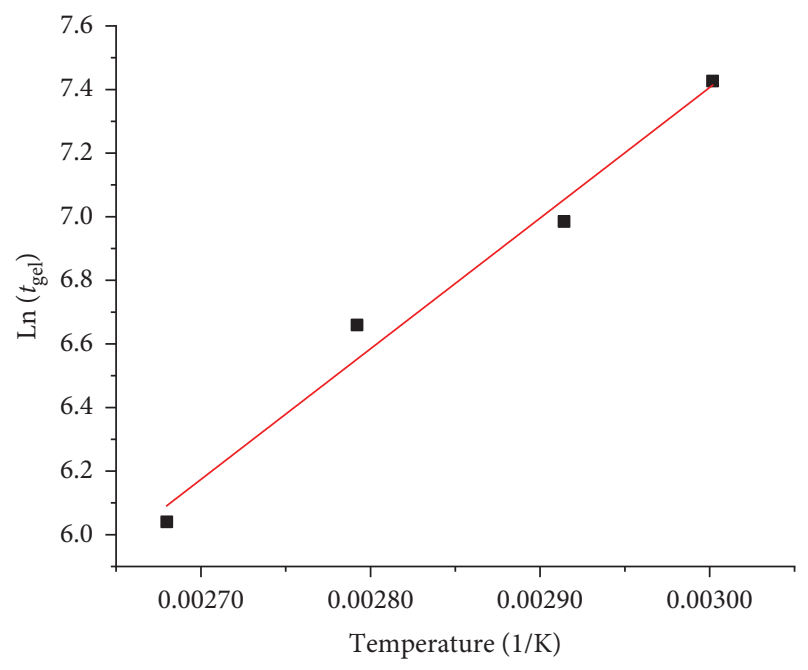

Figure 7: Resin gelation time vs. temperature.

$6.6 \%$ of voids. It consisted of 77.8 wt. $\%$ of PET pellets and 22.2 wt.\% of hollow glass microspheres. Table 4 shows the mass percentage content of each component.

\subsubsection{Density and Mechanical and Thermal Properties of the} Designed Formulations. The density of the polymer concrete was determined as the bulk density by means of a pycnometer. Mechanical properties were obtained as described in the experimental section taking into account the corresponding ASTM standards.

Results are shown in Table 5. Thermal properties were obtained by means of differential scanning calorimetry (DSC).

Formulation 1 presented the highest compressive and tensile strength. Nevertheless, Formulation 2 exhibited the highest specific compressive strength. The better performance of the Formulation 1 could be explained given the content of sand by analyzing the problem with the rule of mixtures [17]. Since the volume fractions in both formulations are the same, as well as the mechanical properties of the epoxy system, what it is assumed is that the mechanical properties of the sand + quartz aggregates mixture [31] are greater than the PET pellets + hollow glass microspheres aggregates mixture [32]. This would explain the higher mechanical properties of Formulation 1 when comparing to a Formulation 2.

Similar results were found by Nóvoa et al. [17], where two series of polymer mortar formulations were studied, epoxy/sand weight ratio: $20 / 80$ and 25/75. The compressive strength of the first one was $67.8 \mathrm{MPa}$ with a density value of $1.81 \mathrm{~kg} / \mathrm{m}^{3}$. These results are in agreement with the ones obtained for Formulation 1, with $65.1 \mathrm{MPa}$ of compressive strength and a density of $1.90 \mathrm{~kg} / \mathrm{m}^{3}$. The mechanical properties and the density of the formulation with less sand decreased to $58.47 \mathrm{MPa}$ and $1.73 \mathrm{~kg} /$ $\mathrm{m}^{3}$, respectively. In addition to these formulations, different percentages of cork were added in replacement of the sand. Compressive strength clearly decreased with the decrease of sand, losing $68 \%$ of the compressive strength when replacing $45 \%$ of the sand with cork in their first formulation and $53 \%$ in their second formulation. In addition, these authors found an increase in the specific properties when replacing sand with cork. Same results are observed in Table 5, where Formulation 2, with no content of sand, have a specific compressive strength $25 \%$ higher than Formulation 1.

When it comes to the design of lightweight concretes, Formulation 2 reached a compressive strength of $37.3 \mathrm{MPa}$, similar to the value obtained by Nóvoa et al. [17] with the addition of cork, but the density of Formulation 2 is $0.88 \mathrm{~kg} /$ $\mathrm{m}^{3}$ while the density of the formulation presented by Nóvoa et al. [17] was $1.57 \mathrm{~kg} / \mathrm{m}^{3}$.

Reis et al. [11] studied the mechanical properties of a polymer concrete while sand was replaced with shredded PET aggregates. These authors also found that the density decreased with the replacement of sand: an epoxy polymer mortar containing $20 \%$ of PET presented $19.8 \%$ reduction, but the mechanical properties decreased as well. They presented a decrease in the fracture toughness and the elasticity modulus as the PET aggregate content increased and the sand content decreased.

3.2. Finite Element Model Validation. Tensile (positive) and compressive (negative) stress results are presented in Figure 8 for Utility Structure 1 with a wall thickness of $25 \mathrm{~mm}$ with a lateral pressure of adjacent soil of $82 \mathrm{kPa}$. The maximum tensile stresses are represented in red and maximum compressive stresses are in blue.

The effects of the studied pressure condition $(5.5 \mathrm{kPa}$, $82 \mathrm{kPa}$ and $160 \mathrm{kPa}$ ) applied as boundary conditions on the maximum stress values are shown in Table 6 for Utility Structure 1 and the Utility Structure 2 with a wall thickness of $25 \mathrm{~mm}$. Table 7 presents the same results for a wall thickness of $50 \mathrm{~mm}$. These results highlight that, for both wall thicknesses, Utility Structure 2 presented higher displacements and strains compared with Utility Structure 1 at the same pressure. 
TABLE 4: Formulation compositions in mass.

\begin{tabular}{lccccccc}
\hline & Fine sand & Coarse sand & Quartz & Pellets & Hollow glass microspheres & $\begin{array}{c}\text { Resin system } \\
\text { Epoxy }\end{array}$ \\
& & & & & wt.\% & & \\
Formulation 1 & 18.5 & 55.4 & 6.2 & 0 & 0 & 14.8 \\
Formulation 2 & 0 & 0 & 0 & 62.4 & 17.6 & 5.2 \\
\hline
\end{tabular}

TABle 5: Material properties of polymer concrete (PC) systems.

\begin{tabular}{lccc}
\hline Property & & Formulation 1 (epoxy/sand) & Formulation 2 (epoxy/glass/PET) \\
\hline Density & $\mathrm{kg} / \mathrm{m}^{3}$ & 1.90 & 0.88 \\
Compressive modulus & $\mathrm{MPa}$ & 3577.4 & 1886.9 \\
Tensile strength $\sigma_{\mathrm{f}}^{*}$ & $\mathrm{MPa}$ & 25.6 & 10.9 \\
Compressive strength $\sigma_{\mathrm{c}}$ & $\mathrm{MPa}$ & 65.1 & 37.3 \\
Specific compressive strength & - & 34.3 & 42.4 \\
\hline
\end{tabular}

${ }^{*}$ Estimated property from flexural stress (ASTM D $790[26,30]$ ).
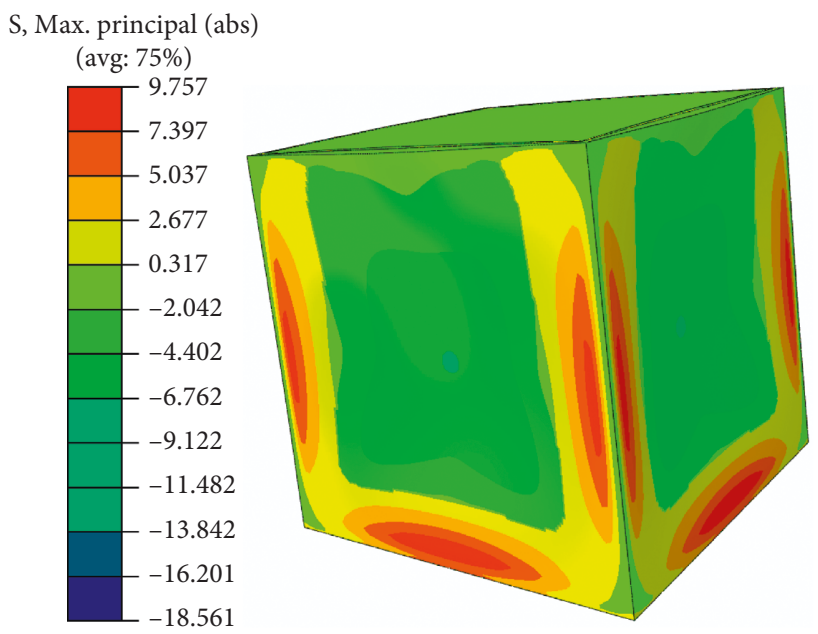

(a)

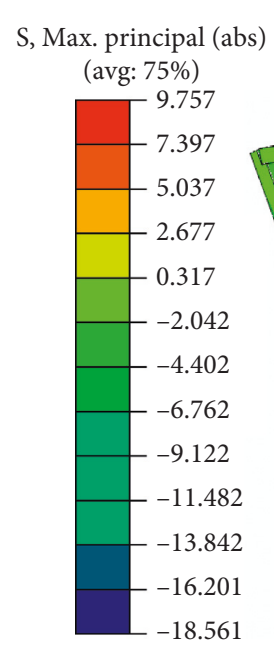

$-18.561$

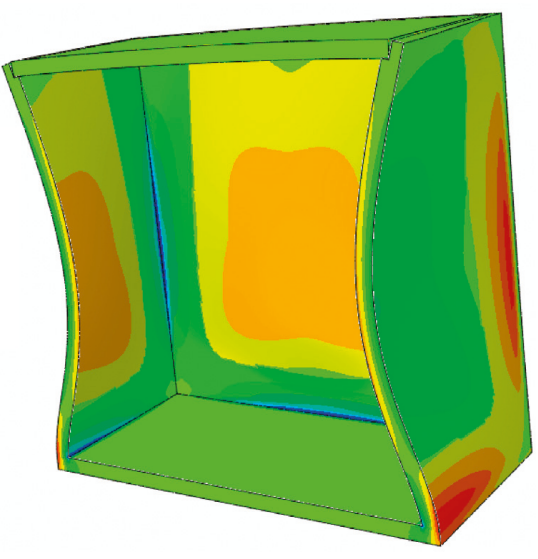

(b)

Figure 8: (a) Tensile (positive) and (b) compressive (negative) stress results for Utility Structure 1 with a wall thickness of 25 mm with a lateral pressure of adjacent soil of $82 \mathrm{kPa}$.

Displacement $(U)$ and strain $(E)$ values are shown in Figures 9(a) and 9(b), respectively for Utility Structure 1 with a wall thickness of $25 \mathrm{~mm}$ and a lateral pressure of adjacent soil of $82 \mathrm{kPa}$, as an example. The highest displacements and strains were observed at the center of the box face.

The influence of the wall thickness on the stress distribution when the lateral pressure of adjacent soil is $82 \mathrm{kPa}$ is presented in Table 8 for Utility Structures 1 and 2. It can be observed again that Utility Structure 2 presents higher displacements and strains when compared with Utility Structure 1 for the same wall thickness.

For service load or working stress design, a safety factor is required. In the present analysis, a safety factor of 2.4 was used based on the literature [33]. The values defined as maximum admissible stresses are $41 \%(1 / 2.4)$ of the compressive strength and $41 \%$ of the tensile strength. These limit values are shown in Table 9.

Results of the shell model used to simulate Utility Structure 1 at a lateral pressure of adjacent soil of $82 \mathrm{kPa}$ predict that the wall thickness should be at least of $25.4 \mathrm{~mm}$ in order to achieve a tensile strength equal or higher than the admissible, to provide a reasonable safety against collapse (Figure 10). In addition, the absolute value of the maximum admissible compressive stress is always significantly higher than stress values sustained by Utility Structure 1 in service within the range of wall thickness values simulated. Hence, in this case, Utility Structure 1 will never collapse due to compressive failure.

The same results for Utility Structure 2 are presented in Figure 11. It can be observed that the wall thickness required to avoid the collapse of Utility Structure 2 under lateral soil load of $82 \mathrm{kPa}$ is higher $(40.0 \mathrm{~mm})$ when compared to Utility Structure $1(25.4 \mathrm{~mm})$. This is consistent with the higher values shown in Tables 7 and 8 . With a smaller wall thickness, Utility Structure 1 overcomes the maximum admissible tensile stress. This means that it is possible to obtain the same performance with a smaller wall thickness, hence, less material volume, when the chosen material to 
TABLE 6: Simulation results for Utility Structure 1 and Utility Structure 2 with a wall thickness of $25 \mathrm{~mm}$ as a function of soil pressure.

\begin{tabular}{|c|c|c|c|c|c|c|}
\hline \multirow{2}{*}{$\frac{\text { Pressure }(\mathrm{kPa})}{\text { Utility Structure }}$} & \multicolumn{2}{|c|}{5.5} & \multicolumn{2}{|c|}{82} & \multicolumn{2}{|c|}{160} \\
\hline & 1 & 2 & 1 & 2 & 1 & 2 \\
\hline Maximum tensile stress $\sigma_{\mathrm{f}}(\mathrm{MPa})$ & 0.6 & 0.6 & 9.7 & 9.7 & 19.0 & 19.0 \\
\hline Maximum compressive stress $\sigma_{\mathrm{c}}(\mathrm{MPa})$ & 0.4 & 0.4 & 6.8 & 6.8 & 13.0 & 13.0 \\
\hline Maximum displacement $(U)(\mathrm{mm})$ & 0.15 & 0.5 & 2.3 & 9.2 & 4.5 & 18 \\
\hline Maximum strain $(E)(\mathrm{mm} / \mathrm{mm})$ & $1.4 E-04$ & $4.5 E-04$ & $2.2 E-03$ & $7.2 E-03$ & $4.3 E-03$ & $1.4 E-02$ \\
\hline
\end{tabular}

TABLE 7: Simulation results for Utility Structure 1 and Utility Structure 2 with a wall thickness of $50 \mathrm{~mm}$ as a function of soil pressure.

\begin{tabular}{|c|c|c|c|c|c|c|}
\hline Pressure $(\mathrm{kPa})$ & & & & & & \\
\hline Utility Structure & 1 & 2 & 1 & 2 & 1 & 2 \\
\hline Maximum tensile stress $\sigma_{\mathrm{f}}(\mathrm{MPa})$ & 0.24 & 0.24 & 3.6 & 3.6 & 7.0 & 7.0 \\
\hline Maximum compressive stress $\sigma_{\mathrm{c}}(\mathrm{MPa})$ & 0.1 & 0.1 & 1.5 & 1.5 & 2.9 & 2.9 \\
\hline Maximum displacement $(U)(\mathrm{mm})$ & $2.8 E-02$ & $8.8 E-02$ & 0.42 & 1.3 & 0.83 & 2.6 \\
\hline Maximum strain $(E)(\mathrm{mm} / \mathrm{mm})$ & $5.6 E-05$ & $1.7 E-04$ & $8.4 E-04$ & $2.6 E-03$ & $1.6 E-03$ & $5.0 E-03$ \\
\hline
\end{tabular}
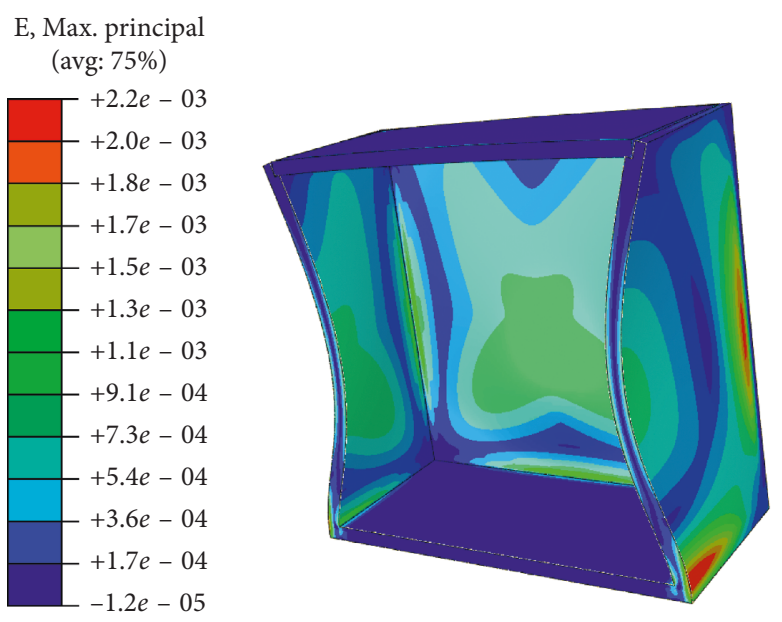

(a)

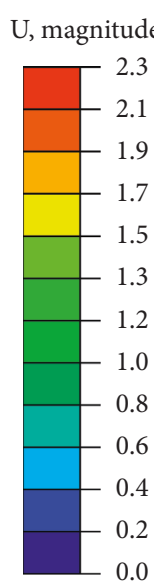

0.0

(b)

FIGURE 9: Simulation results of (a) displacement (U) and (b) strain (E) for Utility Structure 1 with a wall thickness of $25 \mathrm{~mm}$ with a lateral pressure of adjacent soil of $82 \mathrm{kPa}$.

TABLE 8: Simulation results as a function of the wall thickness of Utility Structure 1 and Utility Structure 2 with a pressure of $82 \mathrm{kPa}$.

\begin{tabular}{|c|c|c|c|c|c|c|c|c|c|c|}
\hline Thickness (mm) & \multicolumn{2}{|c|}{12.7} & \multicolumn{2}{|c|}{18.0} & \multicolumn{2}{|c|}{25.4} & \multicolumn{2}{|c|}{40.0} & \multicolumn{2}{|c|}{50.8} \\
\hline Utility Structure & 1 & 2 & 1 & 2 & 1 & 2 & 1 & 2 & 1 & 2 \\
\hline $\begin{array}{l}\text { Maximum tensile } \\
\text { stress } \sigma_{\mathrm{f}}(\mathrm{MPa})\end{array}$ & 39.9 & 39.9 & 19.8 & 19.8 & 9.9 & 9.9 & 4.0 & 4.0 & 2.5 & 2.5 \\
\hline $\begin{array}{l}\text { Maximum } \\
\text { displacement }(U)(\mathrm{mm})\end{array}$ & 22.6 & 70 & 8.0 & 24.7 & 2.9 & 9.0 & 0.8 & 2.4 & 0.4 & 1.2 \\
\hline $\begin{array}{l}\text { Maximum compressive } \\
\text { stress } \sigma_{\mathrm{c}}(\mathrm{MPa})\end{array}$ & 17.0 & 17.0 & 8.5 & 8.5 & 4.2 & 4.2 & 1.7 & 1.7 & 1.1 & 1.1 \\
\hline $\begin{array}{l}\text { Maximum strain }(E) \\
(\mathrm{mm} / \mathrm{mm})\end{array}$ & $9.7 E-03$ & $3.0 E-02$ & $4.8 E-03$ & $1.4 E-02$ & $2.4 E-03$ & $7.5 E-03$ & $9.8 E-04$ & $3.0 E-03$ & $6.0 E-04$ & $1.8 E-03$ \\
\hline
\end{tabular}

TABLE 9: Limit values of compressive and tensile stress.

\begin{tabular}{lcc}
\hline & $\begin{array}{c}\text { Maximum admissible compressive stress }=41 \% \text { of } \\
\text { compressive strength }(\mathrm{MPa})\end{array}$ & $\begin{array}{c}\text { Maximum admissible compressive stress }=41 \% \text { of } \\
\text { tensile strength }(\mathrm{MPa})\end{array}$ \\
\hline Utility Structure 1 & 27.13 & 10.70 \\
Utility Structure 2 & 15.54 & 4.54 \\
\hline
\end{tabular}




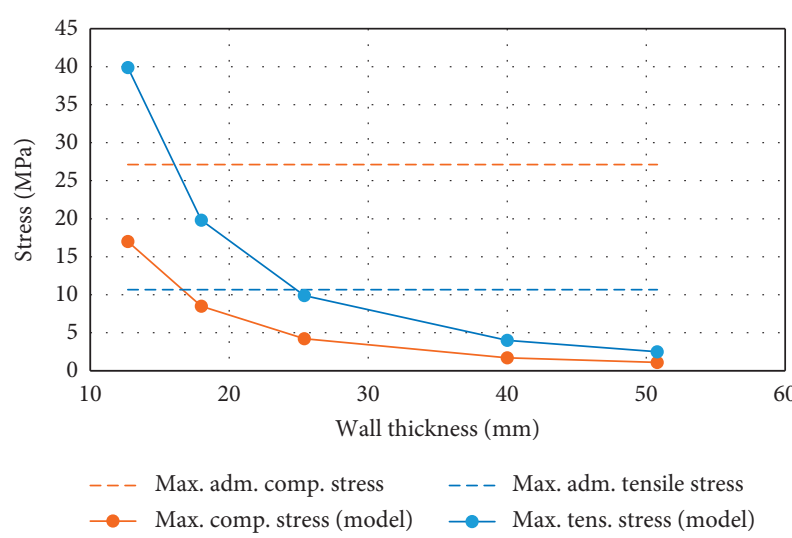

Figure 10: Comparison between maximum tensile and compressive stresses and maximum admissible tensile and compressive stresses for Utility Structure 1 as a function of the wall thickness (shell model).

build the polymer concrete structure is designed with Formulation 1.

It is important to note that an idealized box consisting of six panels of $700 \mathrm{~mm}$ and the minimum admissible wall thickness will weigh $145 \mathrm{~kg}$ and $105 \mathrm{~kg}$, if it is built with Formulation 1 (wall thickness of $25.4 \mathrm{~mm}$ ) and Formulation 2 (wall thickness of $40 \mathrm{~mm}$ ), respectively. A commercially available traditional concrete underground utility structure for the same loading conditions would have a $127-\mathrm{mm}$ (5 in.) wall thickness and a density of $2400 \mathrm{~kg} / \mathrm{m}^{3}$, therefore a significantly heavier weight $(900 \mathrm{~kg})$.

The strains of Utility Structures 1 and 2 when subjected to a lateral pressure of adjacent soil of $82 \mathrm{kPa}$ as a function of their wall thickness is presented in Figure 12. Once more, the strains are bigger for Utility Structure 2 than for Utility Structure 1, being this difference more pronounced as the wall thickness decreases from $40 \mathrm{~mm}$.

In order to more accurately simulate the mechanical behavior of the different Utility Structures, compressive and tensile stresses were simulated and analyzed in a solid model for two wall thicknesses 25.4 and $50 \mathrm{~mm}$. The results obtained with this model are presented in Figures 13(a) and 13(b). It shows that both Utility Structure 1 and Utility Structure 2 with wall thickness of 25 and $50 \mathrm{~mm}$ would never collapse in compression under a lateral soil loading of $82 \mathrm{kPa}$ while Utility Structure 2 with a wall thickness of $25 \mathrm{~mm}$ would fail in tension under the same lateral soil loading. Finally, Figure 14 presents the predicted performance of utility structures with a wall thickness of $25 \mathrm{~mm}$ as a function of lateral soil loads.

As it is observed in Figure 14, Utility Structure 1 with a wall thickness of $25 \mathrm{~mm}$ would never collapse under compression and could endure a pressure of $85 \mathrm{kPa}$ without failure under tension, whereas Utility Structure 2 with the same wall thickness would fail at a pressure value as low as $35 \mathrm{kPa}$.

To summarize, Utility Structure 2 with a wall thickness smaller than $40 \mathrm{~mm}$ is not recommended for service conditions where lateral soil pressures are higher than $82 \mathrm{kPa}$. Based on this study, the best material choice to manufacture

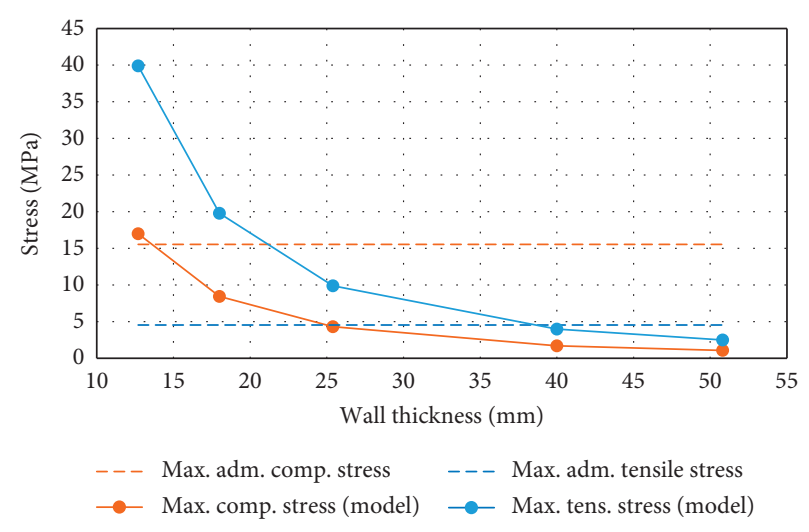

Figure 11: Comparison between maximum tensile and compressive stresses and maximum admissible tensile and compressive stresses for Utility Structure 2 as a function of the wall thickness (shell model).

polymer concrete underground utility structures is the Formulation 1 system, which was named as Utility Structure 1. This structure could even withstand typical in-service pressures with only one-sixth of the weight of a conventional concrete box.

\section{Summary and Conclusions}

Two different formulations were studied to develop a polymer concrete utility structure for an underground application such as optical fiber connection boxes.

Firstly, the polymeric system (epoxy/hardener) was selected based on maximum reaction heat and transition temperature $\left(T_{\mathrm{g}}\right)$ values. Two aggregate systems, one traditional and the other ultralightweight, were optimized to obtain a continuous particle size distribution with minimum void content. With the traditional aggregate system and the epoxy/hardener selected ratio, a formulation was designed (Formulation 1). In addition, with the ultralightweight aggregate system and the epoxy/hardener selected ratio, another formulation was designed (Formulation 2). The maximum service temperature of the polymer concrete of both formulations was set at $45^{\circ} \mathrm{C}, 15^{\circ} \mathrm{C}$ below the $T_{\mathrm{g}}$, in order to avoid the significant stiffness loss that would occur if the $T_{\mathrm{g}}$ was reached in service.

Based on the mechanical properties obtained from samples casted with Formulation 1 and Formulation 2, a structural analysis of an underground utility structure (Utility Structure 1 with the mechanical properties of Formulation 1 and Utility Structure 2 with the mechanical properties of Formulation 2) was also carried out in order to determine which formulation would represent the best performance for underground applications subjected to typical soil pressure values.

Simulation results were developed employing as input the experimental mechanical properties of each formulation in order to obtain the most accurate FEM model. Utility structures, simplified as cubic boxes, were simulated as a $700-\mathrm{mm}$ side cube with a variable wall thickness. From the FEM results, it can be concluded that Utility Structure 2, 


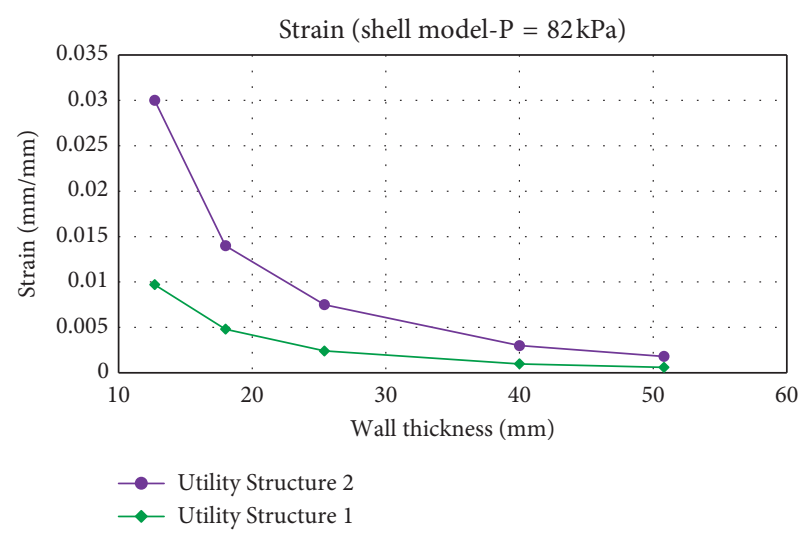

(a)

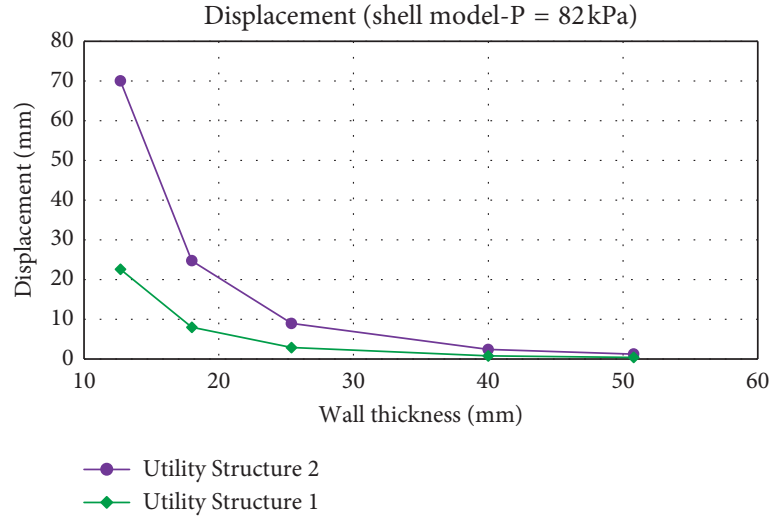

(b)

FIGURE 12: (a) Strain and (b) displacements of Utility Structure 1 and Utility Structure 2 with a lateral pressure of adjacent soil of $82 \mathrm{kPa}$ as a function of their wall thickness.

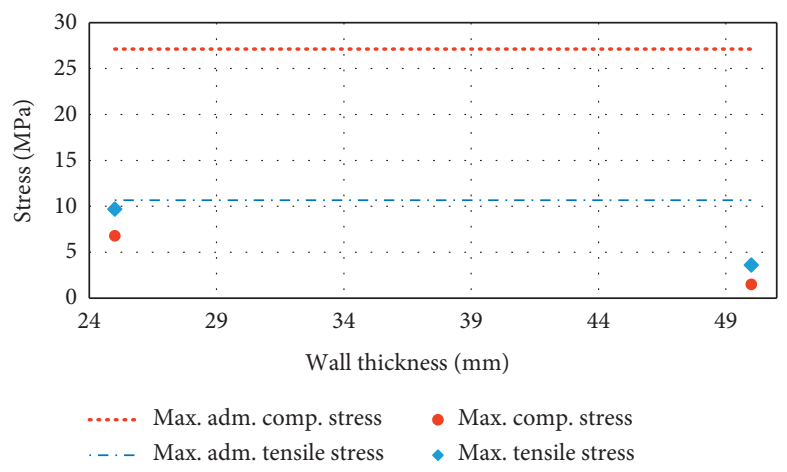

(a)

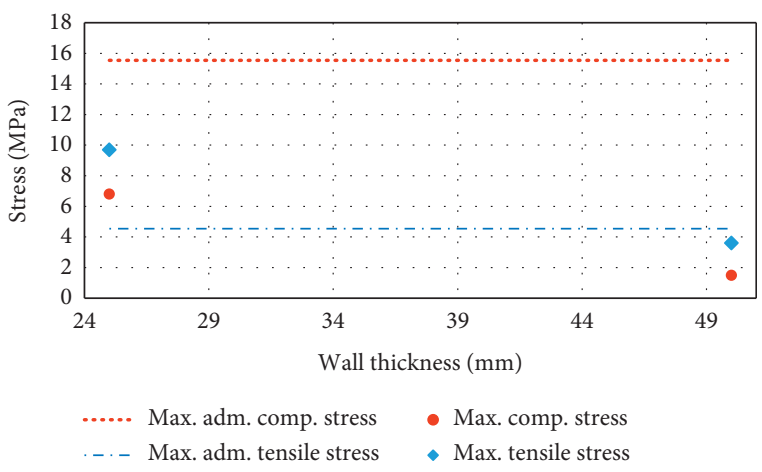

(b)

FIGURE 13: Comparison between maximum tensile and compressive stresses and maximum admissible tensile and compressive stresses for (a) Utility Structure 1 and (b) Utility Structure 2 as a function of the wall thickness.

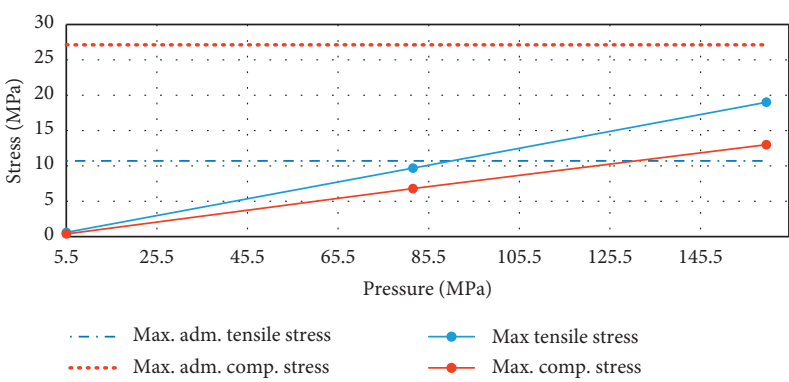

(a)

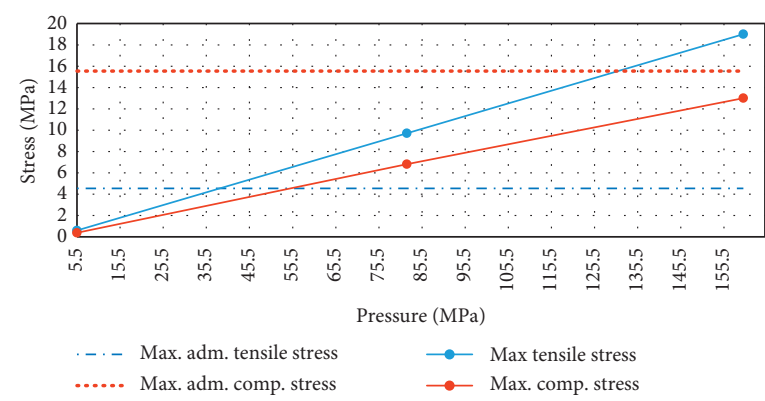

(b)

FIGURE 14: Comparison between maximum tensile and compressive stresses and maximum admissible tensile and compressive stresses for (a) Utility Structure 1 (b) Utility Structure 2 as a function of pressure.

made with the lightest formulation, would not be suitable for applications under soils pressure of $82 \mathrm{kPa}$ or higher with a wall thickness smaller than $40 \mathrm{~mm}$. Nevertheless, even with the biggest wall thickness, the weight of Utility Structure 2 would still be the lowest. Utility Structure 1, made with regular-weight aggregates, could be used under the above conditions as an underground utility structure with a wall thickness of at least $25 \mathrm{~mm}$. Moreover, its weight would be six times lower than a portland cement concrete built to withstand the same soil pressure, with the subsequent important benefits to transportation costs savings. To validate the numerical model, it would be useful to build and tests Utility Structures 1 and 2 with the proposed wall thickness, and it is part of future work. 


\section{Data Availability}

The data used to support the findings of this study are included within the article. In addition, more detailed experimental data are available from the corresponding author upon request.

\section{Conflicts of Interest}

The authors declare that there are no conflicts of interest.

\section{Acknowledgments}

The authors thank the National Research Council of Argentina (CONICET) and the Secretaría de Políticas Universitarias (SPU) from the Ministry of Education of Argentina for funding this project (D9-UBA3135).

\section{References}

[1] D. W. Fowler, "Concrete-polymer materials: how far have we come, and where do we need to go?," in International Congress on Polymers in Concrete, Chapter 1, M. M. RedaTaha, Ed., Springer, Berlin, Germany, 2018.

[2] D. W. Fowler, "Polymers in concrete: a vision for the 21st Century," Cement and Concrete Composites, vol. 21, no. 5-6, pp. 449-452, 1999.

[3] R. Bedi, R. Chandra, and S. P. Singh, "Mechanical properties of polymer concrete," Journal of Composites, vol. 2013, Article ID 948745, 12 pages, 2013.

[4] A. Dimmig-Osburg, "Polymerbetonaus Wüstensand-Ein Projekt der angewandten Forschung, polymer concrete produced with desert sand-a project of applied research," Restoration of Buildings and Monuments, vol. 20, no. 5, pp. 361-370, 2014.

[5] A. Osburg, A. Gypser, and M. Ulrich, Development of Polymer Concrete with Non-standardised Fillers for Innovative Building Materials, Advanced Materials Research, Vol. 1129, Trans Tech Publications, Zurich, Switzerland, 2015.

[6] S. L. Lee, M. A. Mannan, and W. H. Wan Ibrahim, "Polishing resistance of polymer concrete pavement using limestone aggregate," International Journal of Pavement Engineering, pp. 1-9, 2018.

[7] E. Kirlikovali, "Polymer/concrete composites-a review," Polymer Engineering and Science, vol. 21, no. 8, pp. 507-509, 1981.

[8] I. Mironi-Harpaz, M. Narkis, and A. Siegmann, "Peroxide crosslinking of a styrene-free unsaturated polyester," Journal of Applied Polymer Science, vol. 105, no. 2, pp. 885-892, 2007.

[9] Y. Ohama, "Recent progress in concrete-polymer composites," Advanced Cement Based Materials, vol. 5, no. 2, pp. 31-40, 1999.

[10] M. M. Shokrieh, M. Heidari-Rarani, M. Shakouri, and E. Kashizadeh, "Effects of thermal cycles on mechanical properties of an optimized polymer concrete," Construction and Building Materials, vol. 25, no. 8, pp. 3540-3549, 2011.

[11] J. M. L. Reis, R. Chianelli-Junior, J. L. Cardoso, and F. J. V. Marinho, "Effect of recycled PET in the fracture mechanics of polymer mortar," Construction and Building Materials, vol. 25, no. 6, pp. 2799-2804, 2011.

[12] J. M. L. Reis and E. P. Carneiro, "Evaluation of PET waste aggregates in polymer mortars," Construction and Building Materials, vol. 27, no. 1, pp. 107-111, 2012.
[13] M. C. S. Ribeiro, C. M. L. Tavares, and A. J. M. Ferreira, "Chemical resistance of epoxy and polyester polymer concrete to acids and salts," Journal of Polymer Engineering, vol. 22, no. 1, pp. 22-27, 2002.

[14] K. Jafari, M. Tabatabaeian, A. Joshaghani, and T. Ozbakkaloglu, "Optimizing the mixture design of polymer concrete: an experimental investigation," Construction and Building Materials, vol. 167, pp. 185-196, 2018.

[15] B. Zhu, J. Ma, J. Wang, J. Wu, and D. Peng, “Thermal, dielectric and compressive properties of hollow glass microsphere filled epoxy-matrix composites," Journal of Reinforced Plastics and Composites, vol. 31, no. 19, pp. 1311-1326, 2012.

[16] C. Swetha and R. Kumar, "Quasi-static uni-axial compression behaviour of hollow glass microspheres/epoxy based syntactic foams," Materials \& Design, vol. 32, no. 8-9, pp. 4152-4163, 2011.

[17] P. J. R. O. Nóvoa, M. C. S. Ribeiro, A. J. M. Ferreira, and A. T. Marques, "Mechanical characterization of lightweight polymer mortar modified with cork granulates," Composites Science and Technology, vol. 64, no. 13-14, pp. 2197-2205, 2004.

[18] L. Czarnecki and P. Lukowski, "Optimization of polymer cement concretes," in Optimization Methods for Material Design of Cement-Based Composites: Modern Concrete Technology 7, A. M. Brandt, Ed., pp. 231-250, E \& FN Spon, London, UK, 1998.

[19] L. Czarnecki, "Concrete-polymer composites: trends shaping the future," International Journal of the Society of Materials Engineering for Resources, vol. 15, no. 1, pp. 1-5, 2007.

[20] ASTM, ASTM C136 Standard Test Method for Sieve Analysis of Fine and Coarse Aggregates, ASTM, West Conshohocken, PA, USA, 2005.

[21] L. Nunez, F. Fraga, L. Fraga, T. Salgado, and J. R. Anon, "Determination of the optimum epoxy/curing agent ratio: a study of different kinetic parameters," Pure and Applied Chemistry, vol. 67, no. 7, pp. 1091-1094, 1995.

[22] P. M. Stefani, A. T. Barchi, J. Sabugal, and A. Vazquez, "Characterization of epoxy foams," Journal of Applied Polymer Science, vol. 90, no. 11, pp. 2992-2996, 2003.

[23] ASTM, ASTM C 125 Standard Terminology Relating to Concrete and Concrete Aggregates, ASTM, West Conshohocken, PA, USA, 2019.

[24] Y. Ohama, "Polymer concrete," in Developments in the Formulation and Reinforcement of Concrete, Sidney Mindess, Ed., pp. 256-269, Woodhead Publishing, Cambridge, UK, 2008.

[25] R. G. Kelsey and M. Biswas, "Thermomechanical properties of epoxy mortars," Journal of Materials in Civil Engineering, vol. 5, no. 2, pp. 187-197, 1993.

[26] ASTM, ASTM D 790 Standard Test Methods for Flexural Properties of Unreinforced and Reinforced Plastics and Electrical Insulating Materials, ASTM, West Conshohocken, PA, USA, 2017.

[27] ASTM, ASTM C 579 Standard Test Methods for Compressive Strength of Chemical-Resistant Mortars, Grouts, Monolithic Surfacings, and Polymer Concretes, ASTM, West Conshohocken, PA, USA, 2018.

[28] Dassault Systèmes, Abaqus Analysis User's Guide, Dassault Systèmes, Providence, RI, USA, 2014.

[29] ASCE, ASCE Standard, Minimum Design Loads for Buildings and Other Structures, ASCE, Reston, VA, USA, 2005.

[30] T. H. Wee, H. R. Lu, and S. Swaddiwudhipong, "Tensile strain capacity of concrete under various states of stress," Magazine of Concrete Research, vol. 52, no. 3, pp. 185-193, 2000.

[31] N. Bestaoui-Spurr, "Materials science improves silica sand strength," in Proceedings of SPE International Symposium and 
Exhibition on Formation Damage Control, Lafayette, LA, USA, 2014.

[32] T. M. Pique, F. L. Spinazzola, F. Giurich, I. Zapata Ferrero, and A. Vazquez, "Microesferas de vidrio huecas como microagregados para lechadas de cemento petrolero," in Proceedings of 22a Reunión Técnica de la Asociación Argentina de Tecnología del Hormigón, Olavarría, Argentina, 2018.

[33] W. G. Curtin, G. Shaw, G. Parkinson, J. Golding, and N. Seward, Structural Foundation Designers' Manual, John Wiley \& Sons, Hoboken, NJ, USA, 2008. 


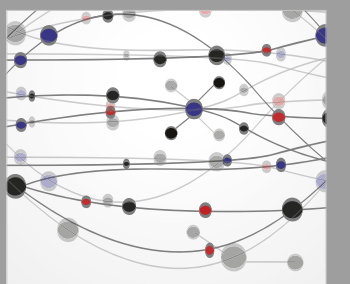

The Scientific World Journal
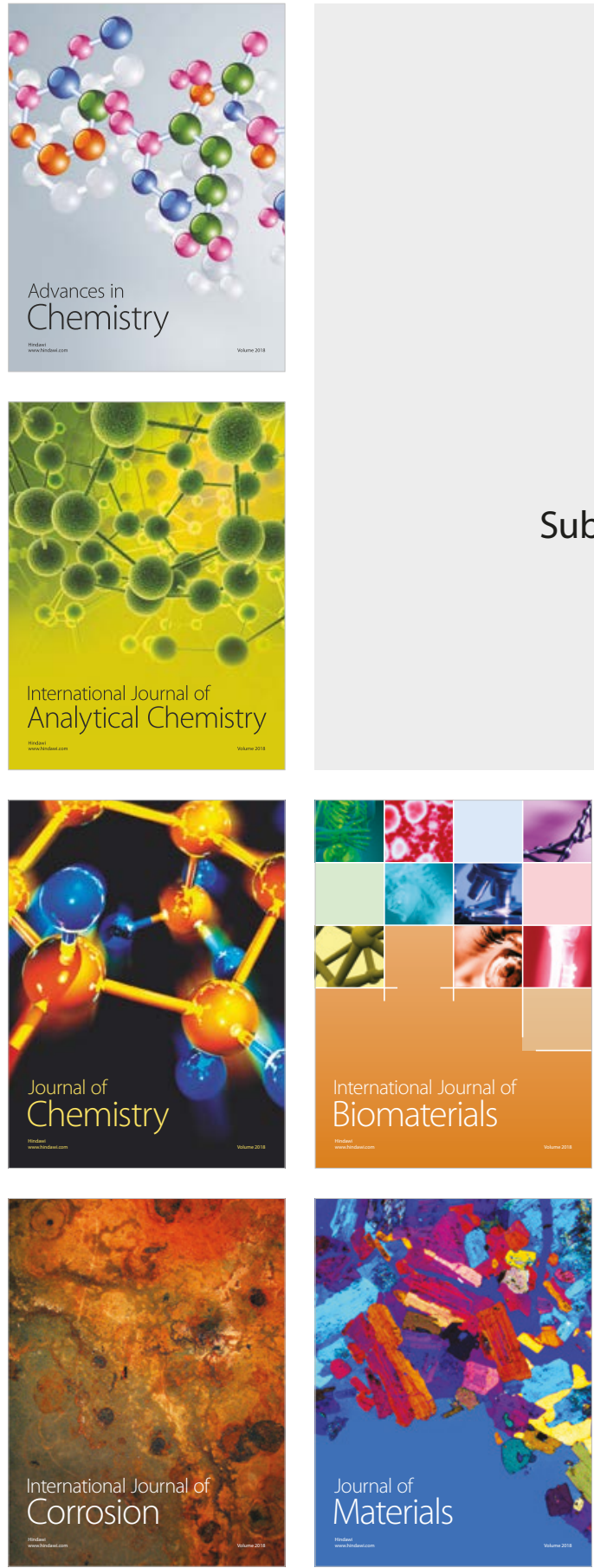

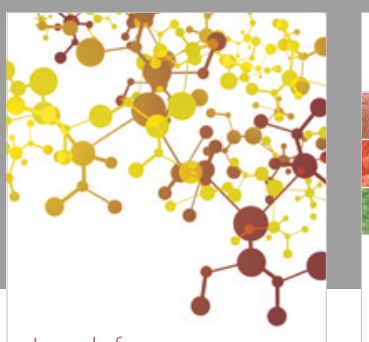

Journal of

Applied Chemistry
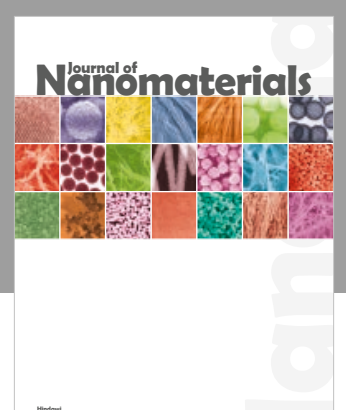

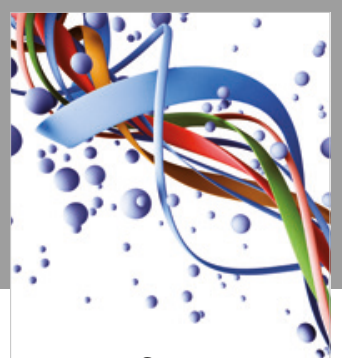

Scientifica

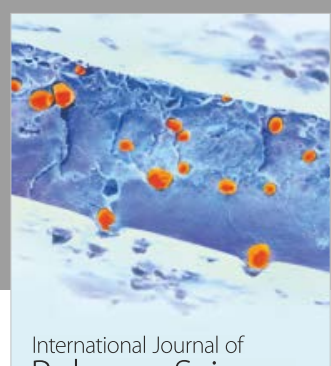

Polymer Science

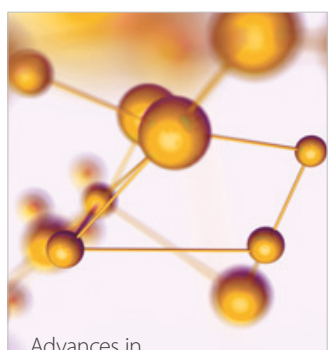

Physical Chemistry
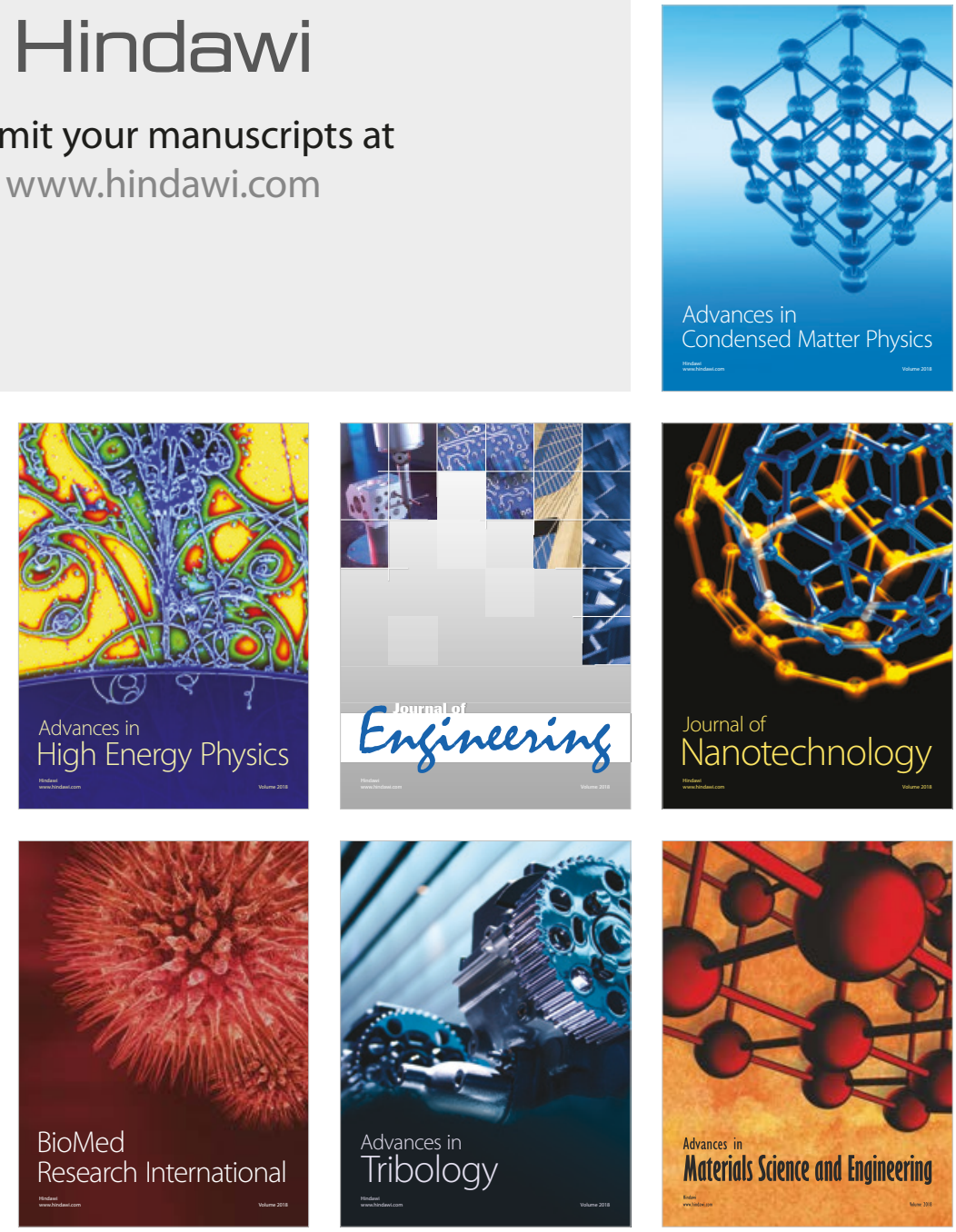